\title{
EDUCAÇĀO GEOGRÁFICA: A PSICOGENÉTICA E O CONHECIMENTO ESCOLAR
}

\author{
Sonia Maria Vanzella Castellar*
}

RESUMO: Este artigo tem como objetivo tratar da aprendizagem e da didática no âmbito da geografia escolar, respaldado nas concepções teóricas da psicogenética. Para tanto, apresentamos alguns aspectos do pensamento geográfico, articulando-o com o saber pedagógico. A partir dos pressupostos da teoria piagetiana propusemos uma nova leitura da didática no ensino da geografia.

Palavras-Chave: Educação. Geografia. Aprendizagem. Saber pedagógico e formação.

\section{GeOgraphic EDUCATION: PSYCHOGENETICS AND SCHOOL KNOWLEDGE}

ABSTRACT: On the bases of the theoretical conceptions of psychogenetics, this paper explores learning and didactics in school geography. It thus presents some aspects of geographical thought, which it articulates with the pedagogical knowledge. It then proposes a new reading of the didactics in the teaching of geography grounded on the assumptions of the theories of Piaget.

Key words: Education. Geography. Learning. Teaching. Pedagogical knowledge and training

* Doutora em educação e professora da Universidade de São Paulo (USP). E-mail: smvc@usp.br 
E

ste artigo tem como objetivo tratar da aprendizagem e da didática no âmbito da geografia escolar, respaldado nas concepções teóricas da psicogenética. Nos últimos anos, as sucessivas discussões sobre o processo de aprendizagem, com base nas teorias construtivistas e socioconstrutivistas, possibilitaram que os educadores tomassem várias posições em relação ao fazer pedagógico, ou seja, em relação ao que se ensina e como se ensina, o que leva a pensar sobre a didática da sala de aula e, conseqüentemente, sobre a maneira como o aluno compreende o conhecimento escolar sistematizado.

Ao tratar da aprendizagem, geralmente esperam-se discussóes acerca de mudanças ou permanências nos conteúdos escolares, mas o enfoque que será dado a este artigo estará também sobre os procedimentos, ou seja, a metodologia da geografia escolar, buscando apresentar um diálogo entre os conteúdos geográficos e a didática.

Para fazer essa análise, cabe resgatar algumas reflexões realizadas por Yves Lacoste no final de 1970 e que compóem parte da história do pensamento geográfico. Um dos principais questionamentos de Lacoste (1998) em relação à geografia escolar, a qual denominou "Geografia dos Professores", refere-se ao fato de essa disciplina estar centrada na memória e na informação. A crítica se dá em função da fragmentação curricular e da maneira como essa área do conhecimento foi desenvolvida - ele afirma que "de todas as disciplinas ensinadas na escola, a geografia é a única a parecer um saber sem aplicação prática fora do sistema de ensino", realidade que ainda hoje se pode constatar em várias situaçóes do cotidiano das salas de aulas.

Nessa perspectiva, surge a necessidade de se investigar, com profundidade, o saber-fazer em geografia, ou seja, a capacidade de aplicação dos saberes geográficos nas atividades escolares, dando destaque para o papel que a disciplina Metodologia do Ensino de Geografia tem na formação docente. Daí a insistência em retomar algumas críticas elaboradas por Lacoste, como a que fez em relação ao ensino mnemônico e informativo na geografia escolar, que acaba por

impor a idéia de que o que vem da geografia não deriva de um raciocínio estratégico conduzido em função de jogo político. A paisagem! Isso se contempla, isso se admira: a lição de geografia! Isso se aprende, mas não há nada para entender. Uma carta! Isso serve para quê? É uma imagem para agência de turismo ou o traçado do itinerário das próximas férias. (Lacoste, 1998, p. 35) 
Essa idéia confirma que, para muitos - leigos ou não - a geografia é uma área do conhecimento escolar que tem como objetivo apenas fornecer informações e que não há necessidade de desenvolver um raciocínio estratégico para aprendê-la. Contudo pensar a geografia como uma disciplina que ensina a memorizar informações soltas é uma idéia equivocada. Por isso construir a idéia de espaço na sua dimensão cultural, econômica, ambiental e social é um grande desafio da geografia, e da geografia escolar. Mais, ainda, pensar que os fenômenos geográficos podem ser analisados articuladamente e em diferentes escalas, o que significa analisá-los conceitualmente, em função de diversas práticas e das representações sociais.

Assim, toda a aprendizagem da geografia na educação básica, entendida como um processo de construção da espacialidade que corresponde a orientar-se, deslocar-se no espaço, pode ser associada aos seguintes objetivos:

1) Capacitar para a aplicação dos saberes geográficos nos trabalhos relativos a outras competências e, em particular, capacitar para a utilização de mapas e métodos de trabalho de campo.

2) Aumentar o conhecimento e a compreensão dos espaços nos contextos locais, regionais, nacionais, internacionais e mundiais e, em particular:

- conhecimento do espaço territorial;

- compreensão dos traços característicos que dão a um lugar a sua identidade;

- compreensão das semelhanças e diferenças entre os lugares;

- compreensão das relações entre diferentes temas e problemas de localizações particulares;

- compreensão dos domínios que caracterizam o meio físico e a maneira como os lugares foram sendo organizados socialmente;

- compreensão da utilização e do mau uso dos recursos naturais.

Esses objetivos estão relacionados com um método de análise do saber geográfico e indicam novas possibilidades de se alterar o currículo da geografia escolar e, conseqüentemente, a forma de se pensar o conhecimento geográfico. Eles vão além dos conteúdos, pois incorporam objetivos procedimentais e atitudinais, contribuindo para ampliar a concepção de currículo existente nas escolas. Todas as tentativas são em direção a renovações que implicam mudanças na postura, na linguagem e nas atividades 
Educação geográfica: a psicogenética e o conhecimento escolar

de aprendizagem necessárias para que o aluno reflita sobre a realidade, a sociedade e a dinâmica do espaço. No entanto o discurso praticado nos séculos XIX e XX continua a ser reproduzido até hoje. Por isso a geografia escolar ainda aparece no currículo como sendo aquela área de conhecimento de menor aplicação prática fora da escola, mesmo que essa situação receba críticas desde meados de $1980 .{ }^{1}$

Com a renovação da geografia, na década de 1980, a crítica que se fazia era dirigida para a despolitização ideológica no discurso geográfico, inclusive no da geografia escolar. $\mathrm{O}$ desejo maior era fazer com que a disciplina perdesse o rótulo de matéria decorativa, herança deixada pela Geografia Tradicional. Mas, se por um lado essas críticas existem, por outro parece que não foram incorporadas ao cotidiano escolar, porque concretamente as mudanças foram pouco significativas. Por isso não tenho dúvidas de que, principalmente a partir da década 1980, o debate na geografia avançou nas Universidades e estagnou nos currículos escolares.

O diálogo existente entre o pensar pedagógico e o saber geográfico permite afirmar que o aluno vai para a escola e aprende a ler, escrever e contar, o que se ensina com mais competência; no entanto o que menos se ensina é a ler o mundo. E é no ensinar a fazer a leitura do mundo e, portanto, no como ocorre esse processo de aprendizagem que se poderia retirar da geografia esse rótulo de matéria decorativa. Mas qual é o significado dessa leitura para os alunos do ensino básico? Saber ler uma informação do espaço vivido significa saber explorar os elementos naturais e construídos presentes na paisagem, não se atendo apenas à percepção das formas, mas sim chegando ao seu significado. A leitura do lugar de vivência está relacionada, entre outros conceitos, com os que estruturam o conhecimento geográfico, como, por exemplo, localização, orientação, território, região, natureza, paisagem, espaço e tempo. Nesse sentido, Lacoste (1998, p. 55) questiona:

Por que não compreender a diferença entre uma carta em grande escala e uma outra em pequena escala e se perceber que não há nisso apenas uma diferença de relação matemática com a realidade, mas que elas não mostram as mesmas coisas? Por que não aprender a se orientar, a passear na floresta, na montanha, a escolher um determinado itinerário para evitar uma rodovia que está congestionada?

Para orientar-se, perceber as distâncias, localizar-se e compreender os fenômenos o aluno deve ler a paisagem e não apenas desenhar mapas. 
Deve começar a estabelecer relaçóes entre os lugares, a ler os fenômenos em diferentes escalas, mobilizando o raciocínio e educando o olhar para que possa fazer a leitura do espaço vivido. O saber agir sobre o lugar de vivência é importante para que o aluno conheça a realidade e possa comparar diferentes situaçôes, dando significado ao discurso geográfico - isso seria a concretização da educação geográfica, do mesmo modo que ocorre com a Matemática, a Física, ou outras áreas do conhecimento escolar.

E é por isso que inicio este artigo provocando uma reflexão que traz questôes não muito novas do ponto de vista histórico, mas que continuam atuais em função da falta de mudanças na postura do docente em relação ao como, para quê e para quem ensinar geografia escolar.

\section{A importância de Piaget no ensino de geografia}

Como foi dito, as questôes trazidas para esta análise envolvem o como, para quê e para quem ensinar geografia escolar e, por isso, a aprendizagem e a didática da geografia, na perspectiva da epistemologia genética de Piaget, e serão relacionadas com o processo de aprendizagem (em geografia).

Para Piaget, a aquisição do conhecimento deve ser compreendida como um processo de autoconstrução contínua; a gênese do conhecimento é explicada através da função adaptativa dos sujeitos em sua interação com o meio. Esse processo ocorre por meio dos esquemas: são assimilados novos aspectos da realidade e, em caso de dificuldade de ajuste, ocorre o desequilíbrio necessário que suscita a modificação de esquemas, até que se chegue à sua acomodação (Hernandez, 1998, p. 135).

A assimilação e a acomodação constituem dois pólos de equilibração do pensamento da criança. A representação (imitação, jogos, desenhos), por exemplo, é um jogo de assimilações e acomodações que ocupa toda a primeira infância, principalmente no momento em que o aluno está estabelecendo comparações entre o imaginário e o real, e aparece de maneira mais significativa na linguagem verbal e nos desenhos. Nestes últimos, o que o aluno desenha é o significante; o significado é o que ele pensa. Essa relação entre significante e significado é importante para a geografia uma vez que auxilia no entendimento da legenda, quando o aluno deve decodificar os signos utilizados em um mapa cognitivo.

O construtivismo epistemológico preocupa-se com o que conhecemos e como alcançamos esses conhecimentos. $\mathrm{Na}$ epistemologia genética 
Educação geográfica: a psicogenética e o conhecimento escolar

estudam-se os mecanismos e processos que os sujeitos atravessam na passagem dos estados de menor conhecimento aos estados de maior conhecimento (Piaget, 1979, p. 16), avaliando-se esses sujeitos pelo grau de conhecimento científico adquirido e compreendido, e não pela quantidade de informações conteudísticas sem significado que possam acumular.

A aprendizagem é vista como um processo de interação social que gera uma adaptação das estruturas mentais do sujeito, ou seja, é um processo de tomada de consciência, pelo educando, das propriedades dos objetos e das suas próprias ações ou conhecimentos aplicados aos objetos. Desse modo, a passagem de um nível de conhecimento a outro se realiza por meio da interação de fatores internos e externos, mais concretamente da experiência física e lógico-matemática, o meio e a interação social, as experiências afetivas e, sobretudo, a tendência à equilibração (equilíbrioconflito-novo equilíbrio).

Uma vez que ocorre o desenvolvimento cognitivo, se estabelece uma seqüência de estágios e subestágios vinculados, cujo traço principal é a integração de ações e conceitos em um processo de estruturação que se entende como sendo a construção de um sistema de ações e conceitos a partir de ações anteriores, sem sistemas prévios. A psicologia genética considera que há um processo interativo entre sujeito e objeto, por meio do qual ocorrerá a construção do conhecimento.

É certo que a criança se encontra com objetos em seu ambiente físico e com noções transmitidas em seu meio social, porém ela não os adota tal e qual, mas os transforma e os assimila às suas estruturas mentais (Piaget, 1978a, p. 35, apud Schoumaker, 1999). Assim, os conceitos centrais da teoria psicogenética permitem apreciar a magnitude de sua potencialidade para entendermos como ocorre o processo de aprendizagem.

Trazer a psicogenética para o cotidiano da sala de aula sempre foi um desafio, até porque não era essa a preocupação de Piaget e seu grupo. Entretanto não podemos deixar de assinalar que algumas idéias iniciais da teoria piagetiana têm sido revistas e reformuladas. No entanto, em relação às implicaçóes educativas dos conceitos da teoria de Piaget, cabe destacar que as investigações psicopedagógicas compóem-se de estudos baseados no ensino e aprendizagem e constituem propostas de ação direta na educação.

Nessa perspectiva, a psicologia genética contribui na fundamentação da educação geográfica desde a educação infantil, em função das noções que estruturam a linguagem cartográfica, a qual se entende constituir 
os primeiros passos para se compreenderem conceitos geográficos. Entre as discussões apresentadas por Piaget, destaco uma que entendo ser de grande importância para o ensino de geografia, a dos esquemas de ação, ou seja, está relacionada com as estruturas mentais e, portanto, com a construção do conhecimento. Para Piaget (1967/2003, p. 15), o

conhecer não consiste em copiar o real, mas agir sobre ele e transformá-lo, de maneira a compreendê-lo em função dos sistemas de transformações aos quais estão ligadas estas ações" e ainda afirma que "para conhecer os fenômenos, o físico não se limita a descrevê-los tal como aparecem, mas atua sobre os acontecimentos, de modo a dissociar os fatores, a fazê-los variar e a assimilá-los a sistemas de transformações lógico-matemáticas.

A epistemologia genética é importante porque nos revela que, para compreender algumas noções que estruturam o conhecimento geográfico, como, por exemplo, o conceito de lugar, é necessário que a criança desenhe o seu lugar de vivência (rua, escola, moradia e outros não tão próximos); mas, para agir sobre ele e transformá-lo, as atividades devem motivá-la a pensar sobre as noções e conceitos, relacionando o senso comum (vivência) com o conhecimento científico. No entanto, para que a criança se aproprie desses conceitos, é importante que desenvolva o raciocínio, a partir da representação simbólica, das relações espaciais, da reversibilidade, e, ao mesmo tempo, se aproprie de noções cartográficas, como legenda, orientação, proporção, ponto de referência, entre outras. Assim a criança vivenciará o processo de letramento cartográfico, uma vez que, além de compreender as noçōes, fará leituras e elaborará mapas mentais, experimentando atividades simbólicas como, por exemplo, compreender o significado dos símbolos e signos que corresponderão aos fenômenos que serão representados nos desenhos e que estarão relacionados e agrupados para que possa ser organizada uma legenda.

Desse modo, a geografia escolar estaria se utilizando da linguagem cartográfica como metodologia para a construção do conhecimento geográfico, trabalhando fundamentos como: dominar as noções de conservação de quantidade, volume e peso, superar o realismo nominal e compreender as relações espaciais topológicas, projetivas e euclidianas, para estruturar esquema de ação. Essas noções auxiliam na construção progressiva das relações espaciais, tanto no plano perceptivo quanto no plano representativo - à medida que as crianças evoluem conceitualmente, vão adquirindo a linguagem e a representação figurada, isto é, segundo Piaget, a função simbólica em geral. 
O pensamento simbólico representacional acontecerá passo a passo quando, por exemplo, a criança, colocada em situações de aprendizagem, mediadas pelo professor, compreender a função dos símbolos e dos signos criados socialmente, como a linguagem de um modo geral ou, no caso da geografia, a linguagem dos mapas. A cartografia escolar tem esse papel, quando se trabalha com as formas geométricas, as cores e outros signos, criando-se condições para a identificação de símbolos que representam fenômenos geográficos e a organização de legenda.

A cartografia, então, é considerada uma linguagem, um sistema-código de comunicação imprescindível em todas as esferas da aprendizagem em geografia, articulando fatos, conceitos e sistemas conceituais que permitem ler e escrever as características do território. Nesse contexto, ela é uma opção metodológica, o que implica utilizá-la em todos os conteúdos da geografia, para identificar e conhecer não apenas a localização dos países, mas entender as relaçóes entre eles, compreender os conflitos e a ocupação do espaço.

Nessa perspectiva, a dimensão cognitiva está no momento da representação de um trajeto (mapa cognitivo ou mental) ou da leitura de um mapa temático, pois são ações que possibilitam à criança relacionar a leitura de mundo e o desenho (mapa cognitivo) com os conceitos de área, tamanho, distância, organizando o pensamento na construção dos conceitos de escala e proporção. Para a elaboração desses mapas, a criança se utiliza da noção de proporção - podendo ser os passos uma referência de medida - com o objetivo de encontrar um determinado objeto ou mensagem. Faz parte da elaboração dos mapas representar os objetos, fenômenos e lugares por meio de signos ou símbolos, e, para fazê-lo, é preciso escolher e hierarquizar o que será representado, de modo que a criança terá de selecionar, agrupar e classificar os símbolos que farão parte da legenda.

No momento em que a criança desenha os lugares de vivência, o espaço perceptivo se estrutura sucessivamente, passando das relaçóes espaciais topológicas às projetivas e euclidianas. Tal construção inicia-se no período sensório-motor e a criança desenvolve ações que motivam a evolução dessas noções espaciais ao se deslocar; essa percepção vai evoluindo à medida que a criança se descentraliza espacialmente, ampliando as suas referências (corpo, diferentes pontos de referência, Sol). A evolução conceitual das relações espaciais topológicas ocorrerá simultaneamente com as projetivas e euclidianas, porque será desenvolvida a noção de proximidade e afastamento (perto e longe), dentro e fora, área, tamanho, parte e todo. 
Já as relações espaciais euclidianas compreendem a noção de distância, área e equivalência entre as figuras, e relacionam-se também com a equivalência entre o real e a representação - desenvolver esse pensamento auxilia no entendimento das noçōes de escala e proporção e de igualdade matemática. Quando se trabalha com escala geográfica não se deve tratá-la apenas como uma questão técnica. Ao se desenvolver esse conceito, além da geometria, deve-se considerar a sua compreensão etimológica e sua importância na elaboração do discurso geográfico. A escala é uma proporção entre o real e o mapa, ou seja, entre a longitude do real e a longitude do mapa, o que significa que estabelece uma relação de equivalência (matemática), e por isso as crianças têm dificuldade em entendê-la, assim se torna importante desenvolver estruturas mentais que auxiliem na sua compreensão.

Quanto à escala, não se avalia apenas a relação de tamanho entre o desenho e a realidade, verifica-se nos desenhos a continuidade ou descontinuidade da área representada: a separação dos lugares, por exemplo, indica que estão isolados, embora façam parte de um conjunto, dando a impressão de que a criança está na fase da incapacidade sintética quanto às relações topológicas. Essas formas de representar os lugares se materializam quando a criança é solicitada a fazer a planta da escola, o trajeto e a planta da casa nessa produção a separação é nítida, faltando à criança capacidade para sistematizar o lugar vivenciado, como se, na sua memória, esses lugares aparecessem fragmentados, apesar de, em sua imagem perceptiva, haver uma visão de continuidade espacial.

Para que a criança inicie seu processo de construção do conceito de escala, é necessário que seja estimulada a perceber, no espaço vivido, as relaçôes topológicas elementares, como separação, ordem e sucessão, proximidade e continuidade das linhas e superfícies. Nesse processo, tanto os aspectos cognitivos como a aprendizagem desempenham um papel importante.

Pela comparação que a criança faz entre objetos ou pessoas do mesmo tamanho e de tamanhos diferentes, e tendo que utilizar a memória na representação do trajeto ou nas plantas - situaçōes em que existe uma relação entre espaço físico e imagem - pode-se perceber se ela possui noção de proporcionalidade, assim como de continuidade, área e linha. À medida que a criança observa e registra os lugares de vivência de situações concretas ou não, mesmo que utilizando a memória para isso, ela pode ser colocada em situaçôes que a levem a atingir níveis cada vez mais elaborados dessas noções, como proporção e área, além das habilidades operatóri- 
Educação geográfica: a psicogenética e o conhecimento escolar

as de comparar tamanhos e áreas diferentes, quantificar os fenômenos, classificá-los e hierarquizá-los - situações que contribuirão para a construção do conceito de escala.

Cabe acrescentar que é só por volta de 8-9 anos de idade que a noção de proporcionalidade vai se constituir e que, paralelamente à noção de proporção, se estrutura a de largura e comprimento, implicando noção de medida, que tem relação com o espaço euclidiano. Mas podem ocorrer casos em que, por volta dos 10 anos, a criança ainda possa apresentar dificuldades nesses conceitos - as idades indicadas para o desenvolvimento de certas capacidades não são normativas, já que esse desenvolvimento depende do nível de estimulação cognitiva a que a criança é exposta.

O olhar geográfico da criança pode ser estimulado ao comparar diferentes espaços e escalas de análises, o que possibilita superar a falsa dicotomia existente entre o local e o global, dicotomia produzida pela ordenação concêntrica dos conteúdos geográficos, e que acaba gerando um discurso descritivo do espaço geográfico. Nesse caso, destaca-se a importância de se estabelecerem relações entre essas escalas, criando condições para que a criança ordene os espaços estudados e compare os fenômenos geográficos, ampliando assim a idéia de escala. Alguns autores, como Batllori (2002, p. 11), chamam a atenção sobre a importância de se eleger uma escala de análise e em seguida outra, para que a criança consiga explicar o processo de generalização dos elementos e fenômenos de uma área, já que, em função da escala, pode-se perder a noção de conjunto ou de detalhes do que está se estudando.

A interpretação dos fenômenos geográficos ganha significado quando a criança entende a diversidade da maneira como se dá a organização dos lugares, quando compreende o conceito de território, por isso reafirmase que a leitura de mapas e a elaboração de mapas cognitivos são imprescindíveis para a compreensão do discurso geográfico. Nessa perspectiva,

el problema de la elección de la escala de análisis fue un tema relevante para a geografía en su momento y sigue aportando ideas para o discurso didáctico. El tema sigue importando en la medida que los niños y niñas de primaria trabajan sólo los mapas de gran escala del medio próximo y escala media de la comunidad o el estado, como si los dos pertenecieran a un mismo nivel de análisis visto con mayor menor detalle y como si ésta fuera la única escala posible para la primaria, como si ésta fuera a realidad, cuando esos mismos niños tienen conocimiento de la escala 
pequeña y de otras escalas medias a través de los medios de comunicación y de las nuevas tecnologías. (Batllori, 2002, p. 11)

A verticalidade e a horizontalidade estão ligados ao ponto de vista, à maneira como a criança observa a posição dos objetos e como consegue representá-los. Ao observar um objeto, a criança o lê numa posição vertical e com visão tridimensional, sendo que ele está em uma posição no espaço; ao desenhá-lo, passa a vê-lo horizontalmente e de forma bidimensional, e a posição do objeto, algumas vezes, é invertida. A construção desse conceito passa por fatores perceptivos que variam de acordo com a idade e com o indivíduo. Essas relações requerem um conjunto de habilidades e estruturas mentais como a reversibilidade e a descentração, pois dependem do ponto de vista do observador. Segundo Piaget \& Inhelder (1993, p. 393),

(...) correlativamente à construção desse sistema de pontos de vista, constitui-se igualmente uma coordenação dos objetos como tal, conduzindo ao espaço euclidiano, à construção das paralelas, dos ângulos e das proporçôes ou semelhanças que fazem a transição entre os dois sistemas. Essa coordenação dos objetos, que supõe a conservação das distâncias, bem como a elaboração da noção de deslocamento, acaba na construção dos sistemas de referências ou de coordenadas.

Apresentamos como um conceito a visão vertical, horizontal e oblíqua a partir da qual a criança vê ou percebe o objeto. Ao determinar a imagem que será desenhada, necessariamente a verticalidade e a horizontalidade organizam o sistema de coordenadas, sendo, pois, fundamentais para a localização dos objetos e lugares no espaço. Para que haja compreensão espacial desse conceito, a criança deve ter desenvolvidas as relações projetivas e euclidianas, sendo que a dificuldade está, muitas vezes, na falta de abstração das formas do objeto.

Tanto a horizontalidade como a verticalidade, entre os 7-8 anos, já começam a se estruturar, mas é por volta dos 9 anos que, hipoteticamente, a criança inicia o processo de construção do sistema de coordenadas, que consiste em relacionar ordenadamente três dimensões ao mesmo tempo: esquerda e direita; acima e abaixo; frente e atrás. Dessa maneira, a criança perceberá o espaço e conseguirá representá-lo, mas para isso é preciso que essas noções sejam garantidas nas atividades de aprendizagem desenvolvidas em sala de aula. Ao buscar essa atitude, o professor tomará as noções cartográficas como referência para estruturar o conhecimento geográfico, o 
que significará ter como referência teórica alguns pressupostos piagetianos, principalmente no que se refere à construção do real e do espaço na criança.

Todo esse processo relacionado à construção do conhecimento permitirá que as crianças desenvolvam o raciocínio estratégico, como afirmou Lacoste. Ao estimular as crianças com atividades que desenvolvem uma evolução conceitual, elas poderão ler e elaborar mapas cognitivos num primeiro momento para, em seguida, ler uma representação cartográfica, compreendendo as convenções internacionais.

\section{A educação geográfica: pensar a didática}

Pensar pedagogicamente os saberes geográficos numa perspectiva metodológica e significativa para os alunos implica desenvolver ações que reestruturem os conteúdos, inovem os procedimentos e estabeleçam com clareza os objetivos. Desse modo, considera-se que a prática educativa da construção de conceitos, atitudes e procedimentos, socialmente, no grupo familiar ou na escola, se faz considerando o conhecimento prévio do aluno, participando do processo de aprendizagem ao

possibilitar conflitos cognitivos durante o trabalho dos alunos com o material escolar e mesmo fornecer informaçóes com o propósito de suscitar a reorganização das idéias prévias das crianças na direção do saber a ser ensinado. (...) É preciso enfatizar os processos formadores das hipóteses e os sistemas conceituais vinculados ao 'saber a ser ensinado', sem renunciar ao pensamento lógico como uma condição necessária para aquela aquisição. (Idem, ibid., p. 25-26)

Castorina (1995) corrobora com essa idéia ao afirmar que é necessário realizar indagaçóes que mostrem efetivamente o desenvolvimento dos mecanismos universais de apropriação, no interior daquela interação com os saberes escolares, e o avanço na reconstrução psicogenética das idéias prévias que correspondem aos conteúdos curriculares em diferentes domínios.

Quando o professor define seus objetivos, estrutura os conteúdos, conceitos e conhece os seus alunos, fica mais fácil perceber e criar condições para que ocorra de fato uma aprendizagem significativa. Desse modo, consideramos que a aula tem uma função relevante, pois é o momento no qual se pode organizar o conhecimento e o pensamento do aluno, a partir de atividade de aprendizagem. Contudo nem todas as açóes docentes garantem uma aprendizagem suficientemente construtivista para todos, mes- 
mo não esquecendo que cada aluno tem seu processo interior, o qual pode ser estimulado quando mediado pelo professor e por seus pares.

$\mathrm{Na}$ discussão sobre o construtivismo epistemológico e o conhecimento cotidiano ainda há muitos equívocos, e o mais comum deles é quando, na prática docente, se considera o cotidiano ou as experiências dos alunos apenas como referência inicial da aula, sendo em seguida colocados de lado ou esquecidos, à medida que o professor retoma os conteúdos/informações sem fazer nenhuma referência a essas experiências - atitude que acaba desmotivando o aluno para a aprendizagem.

Os mapas e as imagens presentes nas aulas são procedimentos, ou seja, estratégias de aprendizagem que possibilitam aos alunos trazer para a discussão o conhecimento prévio e ao mesmo tempo mobilizam habilidades mentais (classificar, analisar, relacionar, sintetizar...) e estimulam a percepção, bem como a observação e a comparação das influências culturais existentes nos diferentes lugares. Permitem ainda que os alunos entendam os mapas como construções sociais que transmitem idéias e conceitos sobre o mundo, apesar da pretendida neutralidade e objetividade que os meios técnicos utilizam para confeccioná-los.

O construtivismo não é a explicação para tudo o que ocorre no mundo e na escola, mas é uma perspectiva epistemológica a partir da qual tenta-se explicar o desenvolvimento humano, e nos ajuda a compreender os processos de aprendizagem, assim como as práticas sociais formais e informais que a facilitam (Juque, Ortega \& Cubero, 1998, p. 162).

O mais difícil da prática docente é provocar a dialética entre o conhecimento cotidiano e o conhecimento acadêmico, potencializando-se assim novos conhecimentos, em um processo no qual os objetivos conjuguem conceitos, esquemas e experiências para garantir uma aprendizagem sólida e significativa, sem diminuir ou aligeirar conteúdos. Por isso pensar uma Educação Geográfica significa superar as aprendizagens repetitivas e arbitrárias e passar a adotar práticas de ensino que invistam nas habilidades: análises, interpretaçóes e aplicações em situações práticas; trabalhar a cartografia como metodologia para a construção do conhecimento geográfico, a partir da linguagem cartográfica; analisar os fenômenos em diferentes escalas; compreender a dimensão ambiental, política e socioeconômica dos territórios.

Ao assumir a teoria construtivista em todas as suas implicações, muda-se a concepção que se tem do papel da escola e da função do profes- 
Educação geográfica: a psicogenética e o conhecimento escolar

sor, pois ela exige que se modifiquem os preconceitos, por exemplo, com relação ao potencial dos alunos para conduzir e construir conhecimentos, ao papel da aprendizagem cooperativa dos outros alunos e ao papel do professor e o seu caráter de mediador.

A ação docente está, portanto, relacionada com os objetivos pedagógicos e educacionais que estabelecemos para desenvolvermos os conteúdos em sala de aula. Se tivermos uma prática que contribua para a evolução conceitual do aluno, atuaremos na perspectiva da construção do conhecimento, refletindo sobre a realidade vivida pelo aluno, respeitando a sua história de vida e contribuindo para que ele entenda o seu papel na sociedade: o de cidadão.

Essa reflexão nos conduz na direção da articulação entre o conteúdo específico e a metodologia do ensino de geografia, revelando que a concepção que temos de geografia deve estar relacionada com a concepção pedagógica.

Assim, o processo de aprendizagem torna-se um desafio permanente para o professor, que deve ter a preocupação de contribuir para desenvolver a capacidade, nele próprio e no aluno, de pensar, refletir, criticar, criar etc. E não deveria ser esse sempre o papel do professor? Caso contrário, tanto ele quanto o aluno serão seres de existência passiva na sociedade.

No processo de aprendizagem, a ênfase tem sido dada ao conteúdo e aos resultados da avaliação, e não em como criar condições para a aprendizagem. Para um processo de aprendizagem fundamentado no construtivismo epistemológico saber e compreender são duas coisas diferentes: o ato simples do saber não considera o aluno como sujeito da sua aprendizagem, além disso, compreender é diferente de relacionar ou elaborar. Partese do pressuposto de que tanto a didática quanto a metodologia do ensino, ou seja, o saber-fazer ou o como o conteúdo é desenvolvido, como o aluno adquire o seu conhecimento e como ele chega a construir os conceitos científicos - são soluções para essas questôes.

Entendemos que os contextos escolares são diferentes no que se refere à dimensão étnica e cultural, mas as preocupações com os saberes escolares são comuns. Nesse sentido, duas questôes retratam os desafios que são colocados na escola: como auxiliar os alunos a conhecer o mundo em que vivemos? O que podemos ensinar do conhecimento geográfico?

A dimensão pedagógica em que acreditamos para realizar um trabalho escolar significativo visa uma prática educativa fundamentada numa 
teoria que possa inovar na metodologia do ensino e no currículo escolar. Mas fica ainda uma outra questão: "como o sujeito que aprende constrói seu conhecimento?”. Entendemos que a geografia escolar vai além da descrição e da informação, aspectos que ainda muitos professores querem reforçar nas escolas. As atividades educacionais e pedagógicas que realizamos no dia-a-dia da escola deveriam ser enquadradas numa concepção de construção do conhecimento.

Por fim, definimos o ensino de geografia como um conjunto de saberes que não só ocupam os conceitos próprios, mas os contextos sociais nos quais se apóiam. Ensinar na perspectiva da construção dos saberes não é apenas dominar conteúdos, mas ter, ao mesmo tempo, um discurso conceitual organizado com uma proposta adequada de atividades, buscando superar os obstáculos da aprendizagem.

Recebido em maio de 2005 e aprovado em julho de 2005.

\section{Nota}

1. “O saber geográfico dominante fala de clima, vegetação, relevo, hidrografia, população, principais atividades econômicas etc. Ao pretender falar de todas as coisas, acaba na verdade produzindo uma visão caótica do mundo, não analisando como as coisas se formam, se produzem, se estruturam e se constituem como totalidade” (Gonçalves, 1987, p. 17). A mesma idéia aparece no artigo publicado em 1988, por Oliveira, onde diz que "os professores e os alunos são treinados a não pensar sobre e o que é ensinado e sim a repetir pura e simplesmente o que é ensinado. O que significa dizer que eles não participam do processo de produção do conhecimento" (p. 28).

\section{Referências bibliográficas}

BATLLORI, R. La escala de análisis: un tema central en didáctica de la geografía. Iber n. 32. Las escalas geográficas, Barcelona, 2002.

CALLAI, H.C. O estudo do lugar e a pesquisa como princípio da aprendizagem. Espaços da Escola, Ijuí, v.12, n. 47, jan./mar. 2003.

CALLAI, H.C.; CALLAI, J.L. Grupo, espaço e tempo nas séries iniciais. In: Castrogiovanni, A.C. et al. (Org.). Geografia em sala de aula: práticas e reflexões. Porto Alegre: UfGRS/AGB, 1998.

CASTELLAR, S.M.V. O ensino de geografia e a formação docente. 
Educação geográfica: a psicogenética e o conhecimento escolar

In: Carvalho, A.M.P. (Coord.). Formação continuada de professores. São Paulo: Pioneira/Thomson, 2003.

CASTELLAR, S.M.V. Alfabetização em geografia. Espaços da Escola, Ijuí, v. 10, n. 37, p. 29-46, jul./set. 2000.

CASTELLAR, S.M.V. A percepção do espaço e a distinção entre o objeto e o seu nome. Caderno CEDES, Campinas, n. 39, p. 88-96, 1996.

CASTORINA, J.A. Psicologia genética: aspectos metodológicos e implicações pedagógicas. Porto Alegre: Artes Médicas, 1988. p. 45-57.

CASTORINA, J.A. et al. (Org.). Piaget e Vigotski: novas contribuições para o debate. Trad. Cláudia Schilling. São Paulo: Ática, 1995.

CAVALCANTI, L.S. Geografia, escola e construção de conhecimentos. Campinas: Papirus, 1998.

COLL, C.; MARTÍ, E. Aprendizagem e desenvolvimento: a concepção genético-cognitiva da aprendizagem. In: Coll, C.; Marchesi, A.; Palacios, J. (Org.). Desenvolvimento psicológico e educação 2: psicologia da educação escolar. Porto Alegre: Artes Médicas, 1979. p. 106.

COLL, C.; MARCHESI, A.; PALACIOS, J. (Org.). Desenvolvimento psicológico e educação 2: psicologia da educação escolar. Porto Alegre: Artes Médicas, 1979.

HERNANDEZ, P. Construindo o construtivismo: critérios para sua fundamentação e sua aplicação instrucional. In: ArnaY, J. (Org.). Dominios do conhecimento, prática educativa e formação de professores. São Paulo: Ática, 1998. p. 127-160.

JUQUE, A; ORTEGA, R.; CUBERO, R. Concepções construtivistas e prática escolar. In: ARnAY, J. (Org.). Dominios do conhecimento, prática educativa e formação de professores. São Paulo: Ática, 1998. p. 162.

LACOSTE, Y. A geografia serve antes de mais nada para fazer a guerra. São Paulo: Ática, 1988.

LERNER, D. O ensino e o aprendizado escolar: argumentos sobre uma falsa oposição. In: Castoriana, J.A. et al. (Org.). Piaget e Vigotski: novas contribuições para o debate. Trad. Cláudia Schilling. São Paulo: Ática, 1995. p. 89. 
LUZ, J.L.B. Jean Piaget e o sujeito do conhecimento. Lisboa: Instituto Piaget, Epistemologia e Sociedade, 1994.

PIAGET, J. Biologia e conhecimento. 4. ed. Petrópolis: Vozes, 2003.

PIAGET, J.; INHELDER, B. A representação no espaço da criança. Porto Alegre: Artes Médicas, 1979.

SCHOUMAKER, B.M. Didáctica da geografia. Porto: ASA, 1999. p. 27. 